07

\title{
Влияние структуры омических контактов на характеристики GaAs/AIGaAs фотоэлектрических преобразователей
}

\author{
(C) А.В. Малевская, В.С. Калиновский, Н.Д. Ильинская, Д.А. Малевский, Е.В. Контрош, \\ М.3. Шварц, В.М. Андреев
}

Физико-технический институт им. А.Ф. Иофрфе РАН, 194021 Санкт-Петербург, Россия

e-mail: amalevskaya@mail.ioffe.ru

(Поступило в Редакцию 8 декабря 2017 г.)

Разработана многослойная система омических контактов для GaAs/AlGaAs фотоэлектрических преобразователей излучения. Предложена и исследована технология „чернения“ омических контактов с целью уменьшения коэффициента отражения оптического сигнала от поверхности многослойного контакта на основе структуры $\mathrm{Ag} / \mathrm{Au} / \mathrm{Ag}$. Достигнуто снижение коэффициента отражения излучения от контактов более чем в 10 раз за счет чернения омических контактов.

DOI: 10.21883/JTF.2018.08.46311.2591

\section{Введение}

В последние годы передача энергии с помощью лазерного излучения (ЛИ) и полупроводниковых фотоэлектрических преобразователей (ФЭП) становится востребованной и получает все более широкое распространение во многих областях [1-6].

При разработке ФЭП, работающих в диапазоне длин волн излучения $600-870 \mathrm{~nm}$, оптимальными материалами являются полупроводниковые соединения $\mathrm{GaAs}$ и GaInAsP. В ФЭП с активной областью на основе GaAs достигнута наибольшая эффективность (более 50\%) при преобразовании лазерного излучения в диапазоне длин волн $800-870 \mathrm{~nm} \mathrm{[7-10]} \mathrm{для} \mathrm{рабочей} \mathrm{длины} \mathrm{волны}$ излучения $808 \mathrm{~nm}$, при внешнем квантовом выходе фотоответа, близком к $100 \%$. Теоретически рассчитанный предел КПД ФЭП на основе GaAs при преобразовании монохроматического излучения с длиной волны $870 \mathrm{~nm}$ составляет 78\% при плотности фототока порядка $10 \mathrm{~A} / \mathrm{cm}^{2}$ [8].

Для повышения диапазона рабочей преобразуемой мощности ФЭП до $100 \mathrm{~W} / \mathrm{cm}^{2}$ и более на фронтальной поверхности осуществляется формирование шин омического контакта. В исследуемых образцах ширина шин

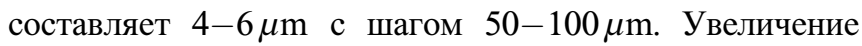
ширины шин более $6 \mu \mathrm{m}$ приводит к росту оптических потерь, вследствие увеличения затенения фоточувствительной поверхности ФЭП, что приводит к снижению КПД. В свою очередь, уменьшение ширины контактных шин приводит к возрастанию сопротивления контактной сетки и росту омических потерь и, как следствие, к уменьшению диапазона рабочей мощности ФЭП.

При осуществлении оптоволоконного подвода лазерного излучения к ФЭП часть излучения, „зеркально“ отраженного от фоточувствительной поверхности и контактных шин ФЭП, попадает обратно в оптическое волокно и ведет к искажению сигнала.
В настоящей работе приведены результаты исследований и разработок постростовой технологии формирования фронтального омического контакта с целью снижения коэффициента отражения оптического излучения от контактных шин.

\section{Методика эксперимента}

Постростовая технология изготовления ФЭП, работающего в диапазоне длин волн 400-900 nm, проводится на основе многослойной гетероструктуры $n \mathrm{GaAs}-n \mathrm{Al}_{x} \mathrm{Ga}_{1-x} \mathrm{As}-n(p)-\mathrm{GaA} s / p-\mathrm{Al}_{x} \mathrm{Ga}_{1-x} \mathrm{As}$, выращенной методом МОГФЭ на подложке GaAs $n$-типа (рис. 1). На фронтальной поверхности фоточувствительной области ФЭП осуществляется формирование полоскового омического контакта к фронтальному слою $p^{+}$-GaAs, стравливаемого до слоя $p$-GaAs $/ p-\mathrm{Al}_{x} \mathrm{Ga}_{1-x} \mathrm{As}$ в местах, свободных от контактов, на области вне контактных шин проводится осаждение антиотражающего

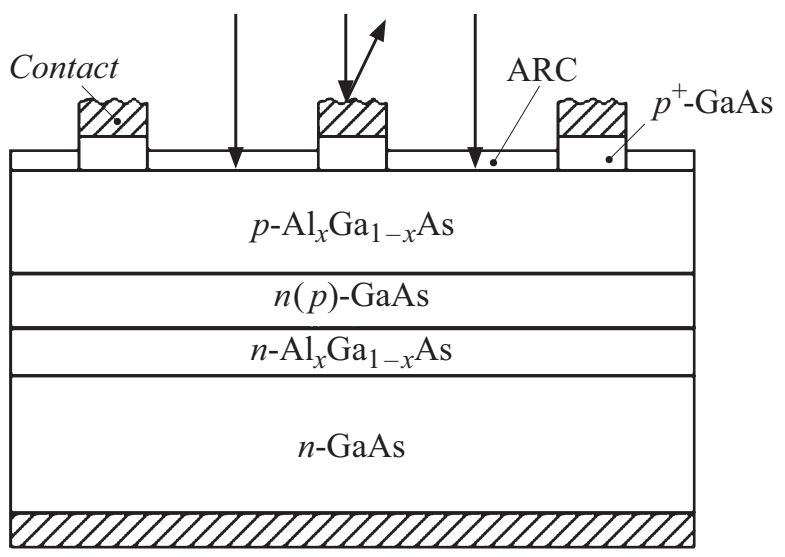

Рис. 1. Структура фотоэлектрического преобразователя с полосковыми фронтальными контактами к слою $p^{+}$-GaAs, стравливаемому в местах, свободных от контактов. 


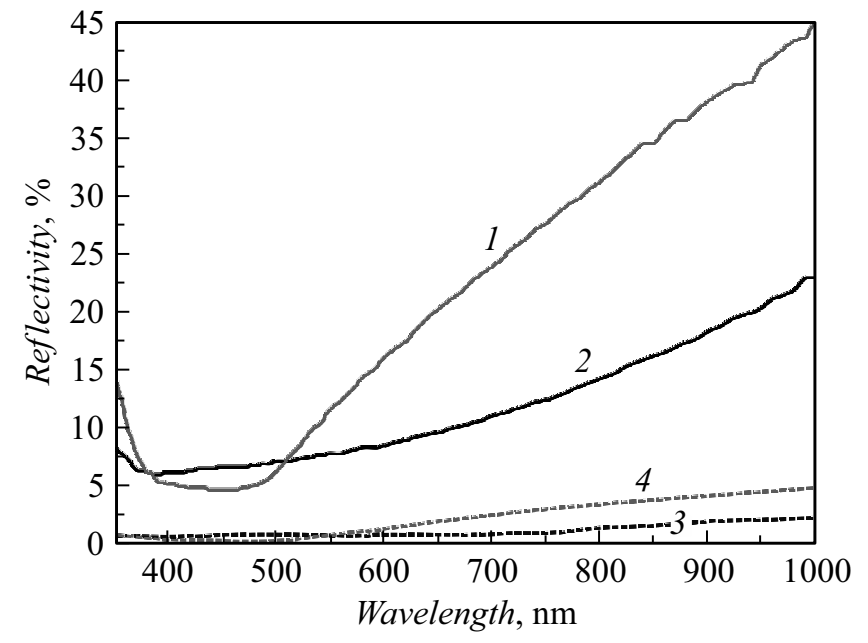

Рис. 2. Спектральные зависимости коэффициентов зеркального отражения от матовой поверхности сплошных контактов с верхним слоем из золота $(1)$, из серебра до чернения (2) и после чернения (3) и после осаждения черного золота (4).

покрытия (ARC на рис. 1). Создание антиотражающего покрытия позволяет снизить коэффициент отражения от фоточувствительной поверхности ФЭП, что приводит к снижению оптических потерь на отражение. При осаждении однослойного антиотражающего покрытия на основе слоя $\mathrm{Ta}_{2} \mathrm{O}_{5}$ или двуслойного покрытия на основе слоев $\mathrm{TiO}_{x} / \mathrm{SiO}_{2}$ достигнуто снижение коэффициента отражения до $1-2 \%$ [11] в спектральном диапазоне $350-1000 \mathrm{~nm}$.

Формирование полоскового омического контакта к фронтальному слою $\mathrm{GaAs}$ р-типа осуществляется в несколько этапов: проводится напыление слоев контактных материалов (например, $\mathrm{AgMn} / \mathrm{Ni} / \mathrm{Au}$ ), затем осуществляется вжигание контактов при темпеpaтуре $360-370^{\circ} \mathrm{C}$ в течение $10-60 \mathrm{~s}$. Применение контактной системы $\mathrm{AgMn}-\mathrm{Ni}-\mathrm{Au}$ позволяет получить низкие значения контактного сопротивления до $1 \cdot 10^{-6}-5 \cdot 10^{-6} \Omega \mathrm{cm}^{2}$ к слою GaAs $p^{+}$-типа; возможно также использование других систем омических контактов. Для увеличения проводимости контактных шин осуществляется электрохимическое утолщение контакта путем осаждения многослойных контактных систем [12]. Были исследованы системы со следующим составом слоев: $\mathrm{Au}, \mathrm{Ag}, \mathrm{Au} / \mathrm{Ni} / \mathrm{Au}, \mathrm{Ag} / \mathrm{Ni} / \mathrm{Au}, \mathrm{Ag} / \mathrm{Au} / \mathrm{Ag}$. Нижний слой серебра или золота выполняется толщиной $2-5 \mu \mathrm{m}$ и обеспечивает высокую проводимость контактной шины, средний слой никеля или золота толщиной $0.1-0.2 \mu \mathrm{m}$ является барьерным. Верхний слой контактных шин выполняется из золота или серебра и подвергается процессу чернения для снижения коэффициента отражения оптического излучения.

Была разработана технология осаждения верхних слоев золота и серебра с шероховатой поверхностью методом электрохимического осаждения. Такие многослойные системы фронтального контакта имеют „матовую“ структуру поверхности, коэффициент „зеркального“ отражения от которой составил $17.5 \%$ для контактов с верхним слоем из серебра и порядка $35 \%$ для контактов с верхним слоем из золота (рис. 2). Измерения коэффициента отражения проводились на образцах со сплошными контактами.

\section{Результаты и обсуждение}

Для снижения коэффициента отражения излучения проведена разработка метода чернения фронтальных слоев омических контактов. Исследованы однослойные контактные системы, полученные методом электрохимического утолщения контактов, состоящие из слоя золота или серебра толщиной $2-5 \mu \mathrm{m}$. При использовании золота технологический процесс утолщения контактов проводится в несколько стадий. Осуществляется электрохимическое осаждение слоя золота толщиной $2-4 \mu \mathrm{m}$, который обеспечивает высокую проводимость контактной шины. Далее для снижения коэффициента отражения оптического излучения непосредственно на слой золота проводится осаждение слоя черненого золота из цианистого электролита золочения с добавлением раствора бихромата калия. Фотография, полученная на сканирующем электронном микроскопе, контактной шины с верхним слоем из черненого золота приведена на рис. 3, a. Для такого контакта достигнуто снижение коэффициента зеркального отражения излучения до $3-4 \%$ в диапазоне длин волны 750-900 nm и до $1-2 \%$ в диапазоне длин волн 350-600 nm (рис. 2). Основным недостатком такой технологии создания черненого покрытия фронтального контакта из золота является его низкая плотность и невысокая механическая стойкость.

Процесс создания контактных шин с черненым серебром включает несколько стадий: на первой стадии проводится процесс электрохимического осаждения слоя серебра, на второй стадии проводится химическая обработка, при которой происходит изменение структуры поверхности Ag и чернение серебра. При проведении химического процесса чернения слоя серебра, происходит сквозное изменение структуры омического контакта, что приводит к снижению проводимости контактных шин. Для предотвращения разрушения слоя омического контакта разработана технология электрохимического осаждения многослойных контактных систем с промежуточным барьерным слоем из $\mathrm{Ni}$ или $\mathrm{Au}$.

При проведении процесса чернения поверхностного слоя серебра в контактной системе $\mathrm{AgMn}-\mathrm{Ni}-\mathrm{Au}$ с верхними слоями $\mathrm{Ag} / \mathrm{Au} / \mathrm{Ag}$ происходит изменение структуры только верхнего слоя $\mathrm{Ag}$, что дает возможность контролировать толщину черненого слоя (рис. $3, b)$. При толщине черненого слоя серебра $0.1-0.5 \mu \mathrm{m}$ достигнуто снижение коэффициента зеркального отражения до $1-2 \%$ в диапазоне длин волн 350-900 nm (рис. 2). 

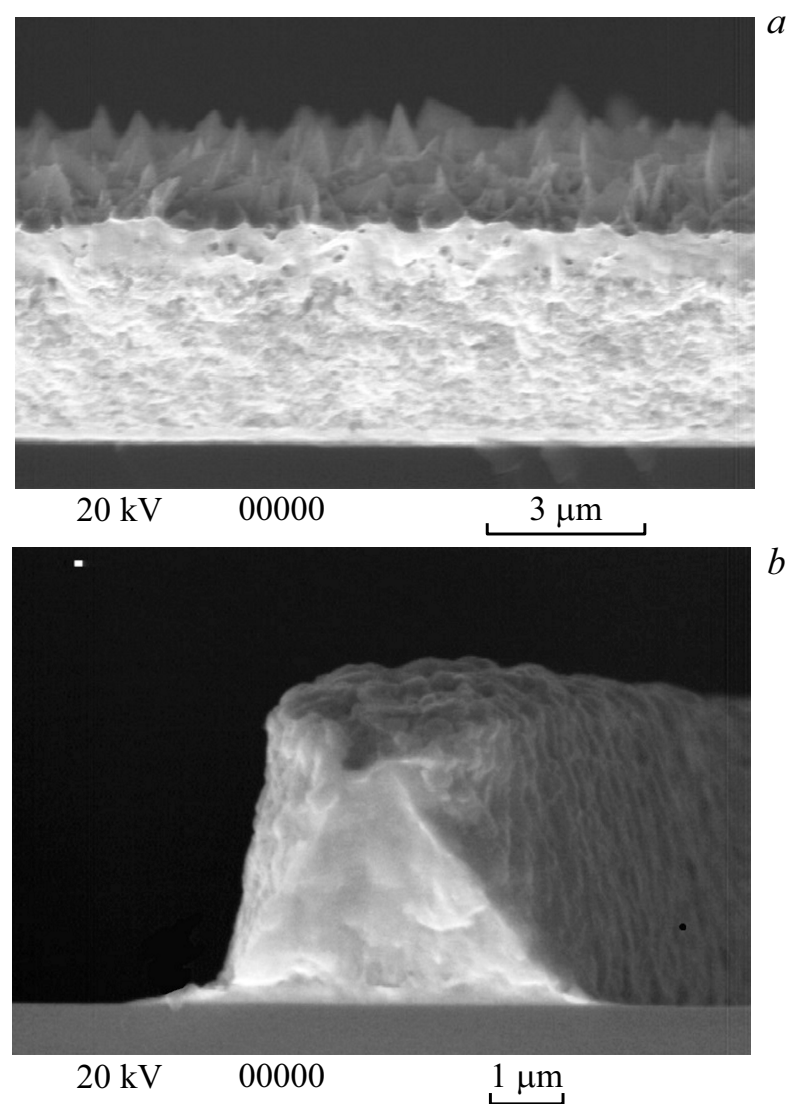

Рис. 3. Полученные на сканирующем электронном микроскопе фотографии однослойной структуры контактной шины с верхним слоем черного золота $(a)$ и многослойной $\mathrm{Ag} / \mathrm{Au} / \mathrm{Ag}$ контактной шины с верхним слоем из „черненого“ серебра $(b)$.

Проведены исследования постростовой технологии чернения поверхности серебряных контактов с использованием нескольких химических растворов:

- раствор на основе $\mathrm{FeCl}_{3}$,

- сочетание раствора на основе $\mathrm{FeCl}_{3}$ и раствора на основе $\mathrm{NaOH} 2 \%$,

- раствор марки КААС 232,

- раствор марки NOIRIT на основе сульфида натрия, гидроксида натрия и сернисто-кислого натрия.

Были проведены исследования влияния разных составов растворов и времени обработки как непосредственно на структуру контактов, так и на величину коэффициента отражения (рис. 4). На рис. 3, $b$ представлена фотография контактной шины с верхним слоем из серебра после чернения в растворе NOIRIT $15 \mathrm{~s}$. Для увеличения адгезии слоя черненого серебра отдельно был исследован метод химической обработки шинных контактов в растворах марки КАAC и NOIRIT при температурах $50-60^{\circ} \mathrm{C}$. Кроме указанных растворов чернение поверхности серебра проводилось и в парах серы.

На полученных пленках черненого золота и серебра на сканирующем электронном микроскопе выявлено, что структура черненых слоев представляет собой со- вокупность гранул размером 0.1-0.5 $\mu \mathrm{m}$. Выявлено, что важную роль играет барьерный слой, который препятствует сквозному чернению и разрушению на всю толщину контактных шин. Проведенные исследования показали, что разные составы растворов и время обработки не оказывают существенного влияния на величину коэффициента отражения. Для оптимизированных режимов коэффициент отражения черненых серебряных контактов не превышал $1-2.5 \%$ (рис. 4). Химическая обработка в растворах в течение $5-15 \mathrm{~s}$ исключает сквозное чернение слоя серебра и обеспечивает сохранение высокой проводимости контактных шин. Наиболее стабильный и воспроизводимый результат был получен при чернении в растворах марки КАAC и NOIRIT.

Так как технологическая операция чернения осуществляется на заключительном этапе постростовой технологии создания ФЭП путем химической обработки фронтального контакта, то было проведено исследование возможного воздействия процесса чернения фронтальных контактов на состояние слоев антиотражающего покрытия и фотовольтаические характеристики ФЭП. Проведены исследования коэффициента отражения от фоточувствительной поверхности ФЭП до и после проведения химической обработки. Установлено, что двуслойное антиотражающее покрытие $\mathrm{TiO}_{x} / \mathrm{SiO}_{2}$ является инертным ко всем использованным химическим методам чернения и сохраняет свои оптические свойства вплоть до плотности мощности светового потока в $200 \mathrm{~W} / \mathrm{cm}^{2}$. Также проводились исследования возможного влияния процессов чернения на свойства полупроводниковой структуры путем оценки темновых ВАХ. На рис. 5 приведены прямые темновые ВАХ ФЭП до процесса чернения, после чернения и после монтажа ФЭП на теплоотводящее керамическое основание. Оценка КПД ФЭП производилась с использованием методики [13] (рис. 6).

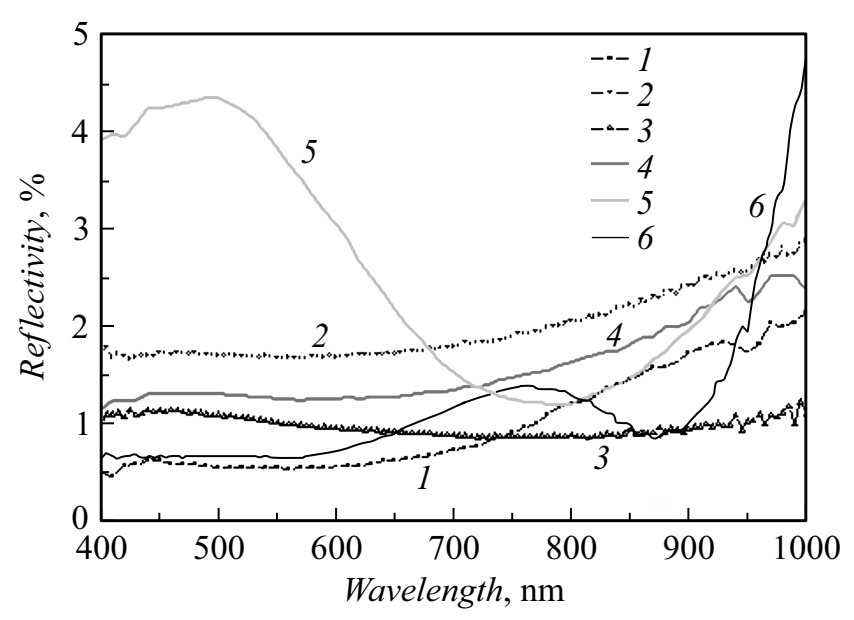

Рис. 4. Спектральные зависимости коэффициента зеркального отражения от поверхности сплошных контактов с верхним слоем из серебра после чернения в растворах: $1-\mathrm{FeCl}_{3}+\mathrm{NaOH}$ $2 \% ; 2$ - марки КАAC 232 (5 min); 3-5 - марки NOIRIT $(5,1 \mathrm{~min}$ и $15 \mathrm{~s}$ соответственно); 6 - в парах серы. 


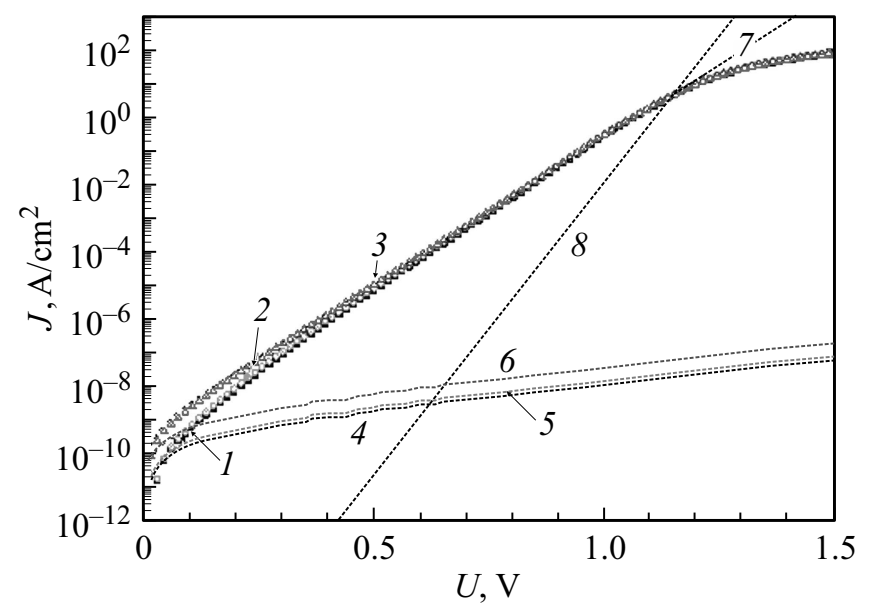

Рис. 5. Прямые темновые ВАХ: 1 - до чернения, 2 - после чернения, 3 - после монтажа черненого ФЭП на теплоотводящее основание (ТО), 4-6 - туннельно-рекомбинационнные избыточные компоненты токопрохождения соответственно: до, после чернения и монтажа ФЭП, 7 - рекомбинационная (СаaНойса-Шокли) компонента токопрохождения, 8 - диффузионная (Шокли) компонента в области пространственного заряда $p-i-n$-перехода ФЭП с диаметром фоточувствительной области $500 \mu \mathrm{m}$.

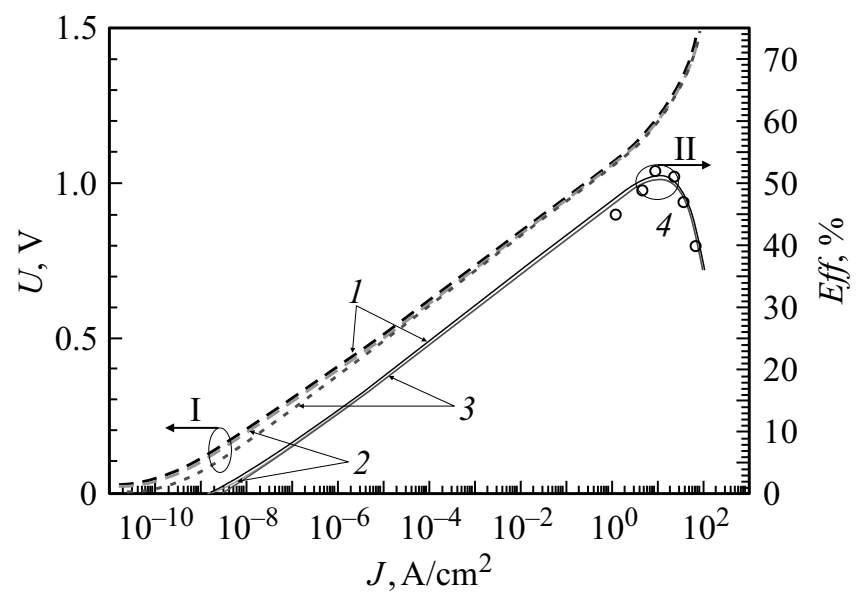

Рис. 6. Зависимости прямых темновых $\mathrm{BAX}$ (I) и КПД от плотности тока генерации (II) для ФЭП: 1 - до чернения, 2 - после чернения, 3 - после монтажа черненого ФЭП на теплоотводящее основание и $4-$ КПД ФЭП после чернения и монтажа на теплоотводящее основание.

Для анализа темновых BAX (рис. 5) использовалась трехкомпонентная экспоненциальная модель:

$$
J=\sum_{i=1}^{n=3} J_{0 i}\left(\exp V_{\varphi} / A_{i} \varepsilon-1\right),
$$

где $\varepsilon \equiv k T / q, V_{\varphi}-$ напряжение на области пространственного заряда (ОПЗ) фотоактивного перехода, $A_{i}$ - диодный коэффициент (коэффициент идеальности), а $J_{0 i}$ - предэкспоненциальный множитель, „ток насыщения".
Значения последовательного сопротивления $\left(R_{s}\right)$ ФЭП и предэкспоненциональных множителей $\left(J_{0}\right)$ до „чернения“, после „чернения“ и после монтажа ФЭП

\begin{tabular}{l|c|c|c|c}
\hline \multirow{2}{*}{ Этапы } & \multicolumn{4}{|c}{ Параметры } \\
\cline { 2 - 5 } & $\begin{array}{c}R_{s}, \\
\mathrm{~m} \Omega \mathrm{cm}^{2}\end{array}$ & $\begin{array}{c}\text { Предэкспоненциональные мно- } \\
\text { жители, „токи насыщения“, }\end{array}$ \\
& 4 & 4.1 & 4.0 & 4.2 \\
\hline До „чернения“ & 4 & 5.3 & 5.0 & 5.7 \\
После „чернения“ & 4 & 12.8 & 5.2 & 5.8 \\
После монтажа \\
ФЭП
\end{tabular}

Видно, что разработанный процесс чернения шин фронтального омического контакта ФЭП не приводит к деградации темновых $\mathrm{BAX}$ и увеличению токов насыщения $J_{0 i}$, соответствующих ,рекомбинационной (Саа-Нойса-Шокли) и ,диффузионной“ (Шокли) компонентам механизмов токопрохождения в ОПЗ $p-i-n$ перехода ФЭП (рис. 5,6 и таблица). Имеет место незначительный рост токов насыщения для „туннельноловушечного, избыточного“ механизма токопрохождения в области плотности токов $\leq 10^{-6} \mathrm{~A} / \mathrm{cm}^{2}$ (рис. 5, кривые 4-6, и таблица). Последовательное сопротивление всей структуры ФЭП с контактами остается неизменным и равным $4 \mathrm{~m} \Omega \mathrm{cm}^{2}$. Из этого следует вывод, что разработанная химическая обработка омических контактов для снижения коэффициента отражения от фронтальной поверхности ФЭП не приводит к деградации структуры и контактов ФЭП в исследованном диапазоне плотности тока. КПД фотопреобразователя на основе используемой $\mathrm{GaAs} / \mathrm{AlGaAs-структуры} \mathrm{достигает}$ значения 51\% при преобразовании лазерного излучения при плотностях генерируемого фототока до $10 \mathrm{~A} / \mathrm{cm}^{2}$, что соответствует преобразованию падающей мощности до $20 \mathrm{~W} / \mathrm{cm}^{2}$ (рис. 6, кривые $1-3$ ).

Исследования процессов чернения фронтального контакта проводились на специальных „тонких“ структурах с малыми значениями темновых токов, что позволяло отслеживать даже незначительное воздействие химической обработки на темновые ВАХ. Однако данные ФЭП имели диапазон рабочих токов до $10 \mathrm{~A} / \mathrm{cm}^{2}$ (рис. 6). Применение разработанных процессов чернения контактов к ФЭП на основе оптимизированных структур позволило „сдвинуться“ в диапазон преобразуемых мощностей ЛИ до $200 \mathrm{~W} / \mathrm{cm}^{2}$ с соответствующим увеличением генерируемых токов до $100 \mathrm{~A} / \mathrm{cm}^{2}$ без снижения КПД ФЭП.

\section{Заключение}

Разработанная технология чернения фронтальных контактов позволяет более чем на порядок снизить коэффициент отражения оптического излучения от слоя серебра в спектральном диапазоне $350-1000 \mathrm{~nm}$. Это 
обеспечивает существенное снижение зеркально отраженного сигнала и шума в приемном оптоволоконном тракте при использовании контактной системы на основе омического контакта с верхними слоями $\mathrm{Ag} / \mathrm{Au} / \mathrm{Ag}$ при чернении верхнего слоя серебра. Установлено, что чернение контактов не приводит к увеличению токов насыщения фотоэлементов.

Исследование выполнено за счет гранта Российского научного фонда (проект № 17-79-30035).

\section{Список литературы}

[1] Андреев В.М. // Современная электроника. 2014. Т. 6. C. 20.

[2] Ванке В.А. // Журнал радиоэлектроники. 2007. Т. 12. С. 98.

[3] Bogushevskaya V., Zhalnin B., Zayats O., Maslyakov Ya., Matsak I., Nikonov A., Obrucheva Ye., Tugaenko V. // Thermal. Eng. 2012. Vol. 59. N 13. P. 975.

[4] Liu Yu., Qin Zh., Zhao Ch. AutoCharge: Automatically Charge Smartphones Using a Light Beam. https://www.microsoft.com

[5] Серебряков В.А. Лазерные технологии в медицине. СПб: СПбГУ ИТМО, 2009. $266 \mathrm{c.}$

[6] Девятков Н.Д. // Электронная техника. Сер. СВЧ-техника. 1993. Т. 1. № 455. С. 67.

[7] Oliva E., Dimroth F., Bett A.W. // Prog. Photovoltaics Res. Appl. 2008. Vol. 16. N 4. P. 289.

[8] Andreev V., Khvostikov V., Kalinovsky V., Lantratov V., Grilikhes V., Rumyantsev V., Shvarts M., Fokanov V., Pavlov A. // Proc. of the 3rd World Conf. on PV Energy Conv. 2003. Vol. 1. P. 761.

[9] Shan T., Qi X. // Infrared Phys. Techn. 2015. Vol. 71. P. 144.

[10] Schubert J., Oliva E., Dimroth F., Loeckenhoff R., Bett A.W. // IEEE Trans. Electron. Dev. 2009. Vol. 56. N 2. P. 170.

[11] Андреев В.М., Гудовских А.С., Задиранов Ю.М., Малевская А.В. Патент № 2436191. 2011. БИ. № 34.

[12] Андреев В.М., Ильинская Н.Д., Калюжный Н.А., Лантратов В.М., Малевская А.В., Минтаиров М.С. Патент № 2419918. 2011. БИ. № 15.

[13] Андреев В.М., Евстропов В.В., Калиновский В.С., Лантратов В.М., Хвостиков В.П. // ФТП. 2009. Т. 43. Вып. 5. C. 671 . 